See Article page 1467.

\section{Commentary: Cracking the code for chronic aortic dissection}

\author{
Eric E. Roselli, MD, FACS, and \\ Lars G. Svensson, MD, PhD
}

Aortic dissection is the late manifestation of a progressive degenerative process involving the aortic media brought on by a variety of different underlying causes, often genetically triggered. ${ }^{1}$ Regardless of the etiology, the aortic wall deterioration has likely progressed for years before the acute intimal tear event in the chronic phase. ${ }^{2}$ For patients who survive the acute event, persistent pressurization of the false lumen frequently leads to accelerated aortic growth, aneurysmal changes, and risk for rupture (Figure 1).

The ideal treatment for aneurysmal changes that occur during the chronic phase of dissection is controversial. Open repair carries a significant risk of morbidity and mortality without eliminating the risk for late reoperation. ${ }^{3}$ Endovascular repair with stent grafting of the true lumen in the chronic phase has been met with limited success depending on aortic anatomy and extent of dissection. ${ }^{4,5}$ The stentassisted balloon-induced intimal disruption and relamination of aortic dissection technique has been described as an adjunct to thoracic endovascular aortic repair during the acute phase. ${ }^{6}$ Now, Faure and colleagues ${ }^{7}$ have described their experience using a similar adjunctive technique of stent-assisted balloon dilatation of the dissection flap in the chronic phase of disease. This is an early experience, with their first 17 patients treated beginning in 2015 with median follow-up of 17 months (range, 3-28.5 months). They demonstrate early safety with no mortality, no aortic ruptures, and minimal complications. We presented our acute outcomes with a similar technique involving balloon fracture of the dissection flap as an adjunct to thoracic endovascular aortic repair in 49 patients with chronic dissection

\footnotetext{
From the Aorta Center and Department of Thoracic and Cardiovascular Surgery, Heart, Vascular, and Thoracic Institute, Cleveland Clinic, Cleveland, Ohio. Disclosures: Authors have nothing to disclose with regard to commercial support. Received for publication Feb 28, 2020; accepted for publication Feb 28, 2020; available ahead of print March 12, 2020.

Address for reprints: Eric E. Roselli, MD, FACS, Aorta Center and Department of Thoracic and Cardiovascular Surgery, Heart, Vascular, and Thoracic Institute, Cleveland Clinic, 9500 Euclid Ave, Desk J4-1, Cleveland, OH 44915 (E-mail: RosellE@ccf.org).

J Thorac Cardiovasc Surg 2021;162:1474-5

$0022-5223 / \$ 36.00$

Copyright (c) 2020 by The American Association for Thoracic Surgery

https://doi.org/10.1016/j.jtcvs.2020.02.115
}

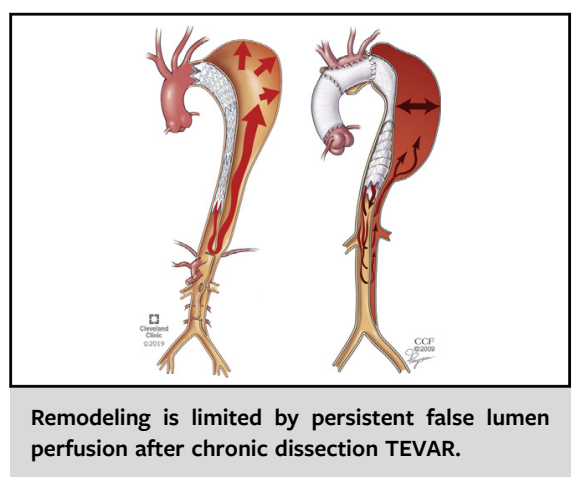

CENTRAL MESSAGE

Stent-assisted balloon dilatation

may be an important adjunct to

true lumen thoracic endovascu-

lar aortic repair in select patients

with chronic distal aortic

dissection.

treated between June 2013 and January 2016, demonstrating that ballooning of the stent graft device in the descending aorta can be done safely (Presented at the American Association for Thoracic Surgery Aortic Symposium, New York, NY, May 12-13, 2016).

Different from what we described, the procedures performed by Faure and colleagues ${ }^{7}$ included bare metal stent coverage across the visceral segment and into the infrarenal aorta, and the ballooning was performed through the entire length of the thoracoabdominal aorta. Additional stenting was performed into branch vessels that were involved with dissection or whose orifice originated from the false lumen (10 renal arteries), and more than half of the patients had additional stenting of both common iliac arteries. Although the follow-up was short, postoperative computed tomography was completed in all patients. False lumen thrombosis was demonstrated through the stent-grafted segment in all patients and through the bare-stented segment in $88 \%$, but in only $24 \%$ of the untreated lower abdominal segment. Nonetheless, there was no further aortic growth documented in any patients and descending thoracic aortic shrinkage was present in all. ${ }^{7}$ This procedure is promising because the achievement of false lumen thrombosis in combination with aortic shrinkage is most consistent with prolonged survival, as has been demonstrated by Mani and colleagues. ${ }^{8}$

The promising findings of this early study ${ }^{7}$ support the need for further exploration of adjunctive techniques to 

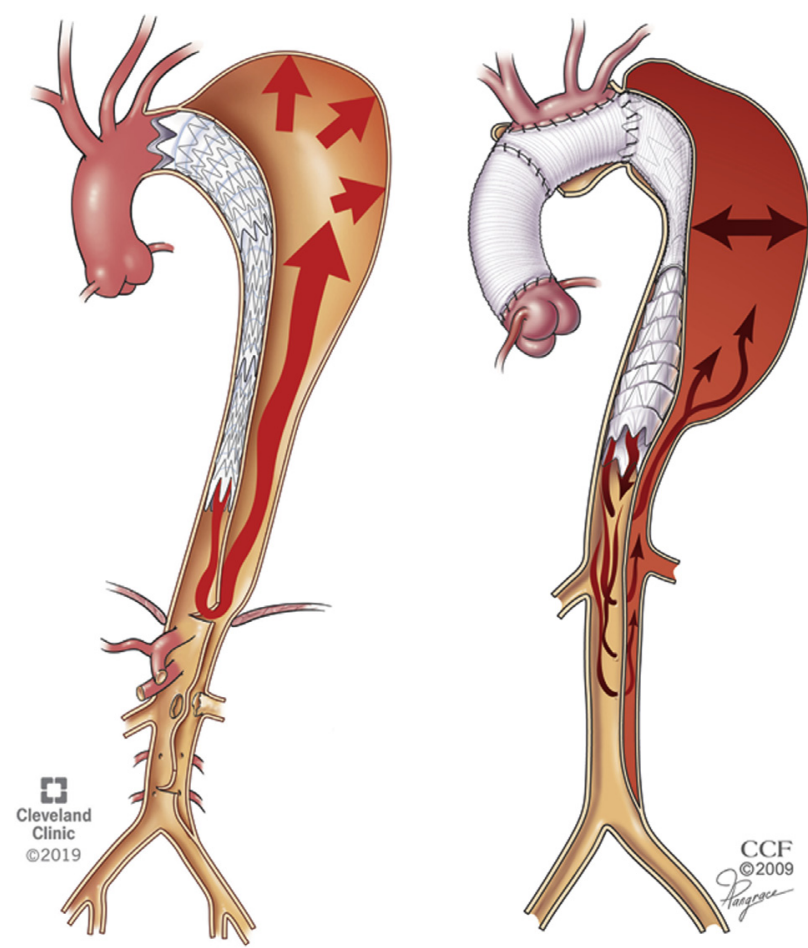

FIGURE 1. Remodeling is limited by persistent false lumen perfusion after thoracic endovascular aortic repair for chronic dissection. Reproduced with permission from Roselli EE, Sepulveda E, Pujara AC, Idrees J, Nowicki E. Distal landing zone open fenestration facilitates endovascular elephant trunk completion and false lumen thrombosis. Ann Thorac Surg. 2011;92:2078-84. Copyright @ Elsevier 2011.

promote positive aortic remodeling and more proactively address the false lumen. Of course, this experience is early and we have much more to learn about the natural history of this disease process, especially after endovascular therapy. All patients in this series were carefully selected by the authors based on their aortic anatomic features. Particularly important was the quality of the proximal and distal thoracic aortic landing zones ( $<42 \mathrm{~mm}$ and at least $2 \mathrm{~cm}$ in length) to allow for full stent-graft expansion to the aortic adventitial diameter. Although all 17 patients were treated during the chronic phase of their disease, it was still quite early in most, with a median time from dissection of only 10 months (more than half within the first year of the original event), and all but 3 patients were treated within 3 years of dissection.?

The bare stent dissection device (Zenith Dissection Endovascular Stent; Cook Medical, Bloomington, Ind) is now commercially available in the United States as well as Europe. Stent-assisted balloon dilatation provides another adjunctive option to treat chronic dissection. Faure and colleagues ${ }^{7}$ are to be congratulated for their bold work in a complex population, including their careful selection of patients and a detailed analysis of early results. As more tools become available to surgeons, a better appreciation of the salient features of disease is needed to guide patient selection, treatment choice, and follow-up imaging to create lifelong precision medicine strategies for treating chronic dissection.

\section{References}

1. Cikach F, Koch CD, Mead TJ, Galatioto J, Willard BB, Emerton KB, et al. Massive aggrecan and versican accumulation in thoracic aortic aneurysm and dissection. JCI Insight. 2018;3:e97167.

2. Peterss S, Mansour AM, Ross JA, Vaitkeviciute I, Charilaou P, Dumfarth J, et al Changing pathology of the thoracic aorta from acute to chronic dissection: literature review and insights. J Am Coll Cardiol. 2016;68:1054-65.

3. Pujara AC, Roselli EE, Hernandez AV, Vargas Abello LM, Burke JM Svensson LG, et al. Open repair of chronic distal aortic dissection in the endovascular era: implications for disease management. J Thorac Cardiovasc Surg. 2012; 144:866-73.

4. Kang WC, Greenberg RK, Mastracci TM, Eagleton MJ, Hernandez AV Pujara AC, et al. Endovascular repair of complicated chronic distal aortic dissections: intermediate outcomes and complications. J Thorac Cardiovasc Surg. 2011; 142:1074-83.

5. Arafat A, Roselli EE, Idrees JJ, Feng K, Banaszak L, Eagleton MJ, et al. Sten grafting acute aortic dissection: comparison of DeBakey Extent IIIA versus IIIB. Ann Thorac Surg. 2016;102:1473-81.

6. Hofferberth SC, Nixon IK, Boston RC, McLachlan CS, Mossop PJ. Stent-assisted balloon-induced intimal disruption and relamination in aortic dissection repair: the STABILISE concept. J Thorac Cardiovasc Surg. 2014;147:1240-5.

7. Faure EM, El Batti S, Sutter W, Bel A, Julia P, Achouh P, et al. Stent-assisted balloon dilatation of chronic aortic dissection. J Thorac Cardiovasc Surg. 2021; 162:1467-73.

8. Mani K, Clough RE, Lyons OT, Bell RE, Carrell TW, Zayed HA, et al. Predictors of outcome after endovascular repair for chronic type B dissection. Eur J Vasc Endovasc Surg. 2012;43:386-91. 